\title{
Title: ADHD and emotional engagement with school in the primary years: investigating the role of student-teacher relationships
}
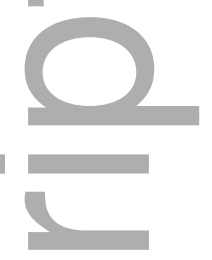

Sophie Rushton ${ }^{\star 1,2}$, Rebecca Giallo ${ }^{1,3}$ and Daryl Efron ${ }^{1,2,3}$

${ }^{1}$ Murdoch Children's Research Institute, Parkville, Victoria, Australia

${ }^{2}$ Centre for Community Child Health, Royal Children's Hospital, Parkville, Victoria, Australia

${ }^{3}$ Department of Paediatrics, University of Melbourne, Parkville, Victoria, Australia

*Corresponding author information: Sophie Rushton, Murdoch Children's Research Institute, 50 Flemington Road, Parkville, Victoria, Australia (e-mail: sophie.rushton@mcri.edu.au).

\begin{abstract}
:
Background. Attention Deficit Hyperactivity Disorder (ADHD) is consistently associated with poor school-level outcomes. Although school engagement is recognised as a protective factor associated with increased academic achievement, school retention/completion, and student wellbeing in the general population, little research has focused on school engagement in children with ADHD.
\end{abstract}

Aims. To explore a model of the relationships between ADHD symptoms at seven years, studentteacher closeness and conflict at 10 years, and emotional engagement with school at 10 and 12 years.

This is the author manuscript accepted for publication and has undergone full peer review but has not been through the copyediting, typesetting, pagination and proofreading process, which may lead to differences between this version and the Version of Record. Please cite this article as doi: 10.1111/BJEP.12316

This article is protected by copyright. All rights reserved 
Sample. Participants were 498 grade one children (mean age 7.3 years), recruited from 43 socioeconomically diverse government primary schools in Melbourne. Follow up occurred at 36 months (mean age 10.5 years) and 54 months (mean age 12 years).

Methods. Data were drawn from a controlled community-based longitudinal study examining the long-term effects of ADHD on children's behaviour, learning and day-to-day living. Data were collected via direct assessment and child, parent and teacher surveys.

Results. Path analysis revealed a significant, negative relationship between ADHD symptoms and emotional engagement with school, which was partially mediated by student-teacher conflict. This remained significant after controlling for differences in ADHD status (ADHD, high risk or control group), ADHD medication use and socio-economic status.

Conclusions. These findings highlight the negative impact of ADHD symptoms on children's emotional engagement with school. Given the role of student-teacher conflict in mediating this relationship, interventions aiming to reduce conflict in the student-teacher relationship may promote school engagement for students with ADHD, with potential to improve longer-term outcomes.

Keywords: Attention Deficit Hyperactivity Disorder, school engagement, student-teacher conflict Acknowledgements: We would like to acknowledge Alisha Gulenc for her practical assistance as coordinator of the Children's Attention Project and Dr Vicki McKenzie for her helpful review and feedback. We would also like to thank the many families and schools for their participation in the study.

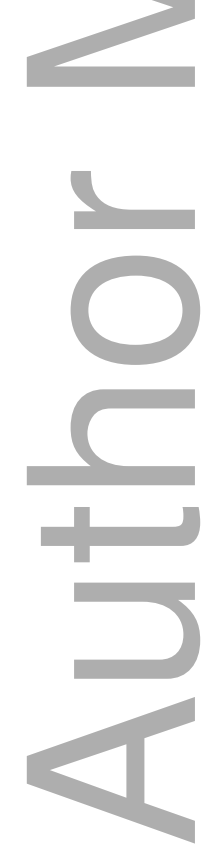




\section{Title: ADHD and emotional engagement with school in the primary years: the role of student-teacher relationships}

With an estimated prevalence of between 5 and 7 per cent worldwide, Attention Deficit Hyperactivity Disorder (ADHD) is the most common neurodevelopmental disorder of childhood (Hinshaw, 2017; Polanczyk, Willcutt, Salum, Kieling, \& Rohde, 2014). ADHD is characterised by developmentally inappropriate levels of inattention, impulsivity and hyperactivity that significantly impair functioning across settings (Voigt et al., 2017) . Research consistently indicates that individuals with ADHD experience a wide range of poor social, emotional, academic and behavioural outcomes across the lifespan (Faraone et al., 2015) and commonly present with comorbid psychological disorders (Cuffe et al., 2015; Efron et al., 2014). Compared with typically developing peers, children with ADHD are more likely to experience poor school-level outcomes including academic underachievement (Daley \& Birchwood, 2010), low school attendance and increased school drop-out (Dembo, Wareham, Schmeidler, \& Winters, 2016; Fried et al., 2016).

School engagement is a widely acknowledged protective factor associated with positive outcomes for students including increased academic achievement, school retention and completion, and greater wellbeing (Fredricks, Filsecker, \& Lawson, 2016). It is commonly conceptualised as a 'meta-construct' involving emotional, cognitive and behavioural components (Fredricks et al., 2004). Emotional engagement includes student feelings about learning and the school they attend (Lam et al., 2014); cognitive engagement includes willingness and motivation to exert effort to learn; and behavioural engagement refers to observable student conduct including participation and active involvement in tasks and activities at school (Fredricks et al., 2016). Early school engagement is considered essential for promoting students' perseverance and success at school (Archambault et al., 2017) as well as for the development of many skills and competencies required for a successful transition to adulthood (Ramos-Díaz et al., 2016; Wang \& Fredricks, 2014). Though school engagement problems are most commonly observed in high school, differences in students' school engagement pathways begin to emerge much earlier (Hancock \& Zubrick, 2015). As students grow older, levels of emotional and behavioural engagement with school generally decline (Lam et al., 2016). However, individual students tend to retain their relative position among their peers, with the least engaged students in the early school years likely to remain the least engaged in secondary school 
(Wylie \& Hodgen, 2012). As such, primary school represents a critical time to intervene to promote students' engagement with school (Archambault, Kurdi, Olivier, \& Goulet, 2016).

Although it is well established that students with ADHD are at high risk of poor educational outcomes (Faraone et al., 2015), little research has focused on school engagement in the context of ADHD (Zendarski et al., 2017). Given that students' school engagement trajectories appear to be set early in their school careers (Hancock \& Zubrick, 2015), it is important to understand more about the relationships between ADHD symptoms and school engagement in the primary years.

\section{ADHD and School Engagement: What Do We Know?}

Many tasks and requirements of school demand proficiency in cognitive functions (i.e., attention, working memory, planning and organisation) that are often impaired in children with ADHD (Martin, 2012). Students with ADHD consistently exhibit more off-task and less on-task behaviour in the classroom (i.e., behavioural engagement) compared with typically developing peers (Imeraj et al., 2013; Kofler, Rapport, \& Alderson, 2008; Steiner, Sheldrick, Frenette, Rene, \& Perrin, 2014; Vile Junod, DuPaul, Jitendra, Volpe, \& Cleary, 2006). However, the evidence in relation to emotional and cognitive school engagement for children with ADHD is substantially less clear.

A search of the literature revealed only two studies investigating all three school engagement components in the context of ADHD (Portilla et al., 2014; Zendarski et al., 2017). The first was a longitudinal study of 388 children aged four to six years recruited from public schools in California (Portilla et al., 2014). Results indicated that higher levels of inattention and impulsivity early in the school year predicted lower overall school engagement at the end of the school year (Portilla et al., 2014). Although data were collected in relation to children's emotional, behavioural and cognitive engagement, only a combined total school engagement score was reported, limiting examination of the role of each school engagement component.

The second study was a cross-sectional, clinic-based study of 130 adolescents aged 12 to 15 years in Victoria (Zendarski et al., 2017). It was reported that students with ADHD exhibited lower behavioural engagement in both the first and third years of high school compared to the state average, however results for cognitive and emotional engagement were mixed. In the first year of high school, students with ADHD were significantly less cognitively engaged compared with the state average, however counter to expectations there was no significant difference on emotional engagement. Students with ADHD unexpectedly reported significantly higher emotional engagement in the third year of high school (compared to the state average), with no significant differences on cognitive engagement at this time. Several limitations may have contributed to this unexpected pattern of findings, including difficulties with the study's operationalisation of the school engagement components (i.e. emotional engagement was operationalised as school connectedness, which may not have adequately captured students' feelings about learning). Untangling the unique contributions of 
the different school engagement components is important to understand how children with ADHD may be best supported to develop positive engagement with school.

\section{Focussing on Emotional Engagement}

The present study aimed to clarify relationships between ADHD symptoms and children's emotional engagement in primary school. The negative impact of ADHD symptoms on behavioural engagement is well established, and cognitive engagement is developmentally difficult to examine in primary-aged children (Archambault et al., 2016; Portilla et al., 2014). Evidence suggests that emotional engagement may act as a precursor underlying subsequent behavioural and cognitive engagement with school (Shernoff, 2016), and thus may be a prime target for intervention for children with ADHD. For these reasons, emotional engagement emerged as a priority focus of investigation. This study aimed to explore a model of the relationships between ADHD symptoms in early primary school and emotional engagement with school in middle and upper primary school.

\section{The Role of Student-Teacher Relationships}

Employing a bioecological framework, school engagement can be conceptualised as a process of reciprocal influence between factors intrinsic to the individual and factors in their social and environmental context (Bakadorova \& Raufelder, 2017; Bronfenbrenner \& Ceci, 1994). Many factors are likely to influence the relationship between children's ADHD symptoms and their emotional engagement with school. Studies have shown that the student-teacher relationship is an important factor for all children (Pianta et al., 2012; Quin, 2017; Skinner et al., 2008), and specifically for children displaying elevated inattention and hyperactivity (Portilla et al., 2014). Evidence from several studies suggests that positive student-teacher relationships foster behavioural, emotional and cognitive engagement in school (Fredricks et al., 2016; Furrer \& Skinner, 2003; Raufelder et al., 2013). However, the attention and behaviour problems that ADHD students experience often strain the relationships these children have with their teachers (Mautone et al., 2011; Rogers et al., 2015). Both boys and girls with ADHD exhibit higher rates of disruptive and off-task behaviours than their typically developing peers, leading to more negative attention from, and interactions with, their teachers (Vile Junod et al., 2006). Research indicates that children with ADHD are more likely to have poorer teacher-student bonds and exhibit lower levels of teacher-student collaboration compared with typical peers (Rogers et al., 2015).

Student-teacher relationships are often conceptualised by examining two dimensions of the quality of the relationship: closeness and conflict (Mason et al., 2017). Closeness captures warmth and positive affect between the teacher and student, whereas conflict captures negativity experienced in this relationship and lack of rapport between teacher and student. Higher levels of inattention and impulsivity in young children at school entry have been associated with both increased conflict and decreased closeness in student-teacher relationships (Portilla et al., 2014), indicating that both elements are important to consider. This study therefore aimed to investigate the role of the student- 
teacher conflict and closeness as mediating factors in the relationship between ADHD symptoms and children's emotional engagement with school.

\section{A Hypothesised Model}

This study sought to explore a longitudinal model of the relationships between children's ADHD symptoms, student-teacher closeness and conflict, and emotional engagement with school during primary school (see Figure 1). It was hypothesised that greater severity of ADHD symptoms at age seven would predict lower levels of emotional engagement with school at age 10, which would be sustained at age 12. It was further hypothesised that greater severity of ADHD symptoms at age seven would predict lower student-teacher closeness and higher student teacher conflict at age 10, and that these in turn would be associated with lower emotional engagement with school at age 10, sustained at age 12 .

Sex differences have been reported in relation to both school engagement and student-teacher relationships in the general student population. However, we did not anticipate that the patterns of associations between the variables in the hypothesised model would differ for boys and girls. As children presenting with ADHD and comorbid disorders often display more severe ADHD symptoms and functional impairments (Steinberg \& Drabick, 2015), it was hypothesised that the presence of comorbid internalising and externalising psychological disorders would moderate the relationships among model variables. That is, that the negative pathways would be strengthened. Similarly, it was hypothesised that ADHD subtype would moderate the relationships among variables in the model, such that the negative pathways would be stronger for children with the combined and hyperactiveimpulsive subtypes, compared to those with inattentive-type ADHD alone. This was expected due to the more disruptive nature of hyperactive-impulsive ADHD symptoms in the classroom, in contrast to the more passive symptoms of inattentive-type ADHD.

\section{Design}

\section{Method}

Data for this study were drawn from the Children's Attention Project, a controlled community-based longitudinal study examining the effects of ADHD on children's behaviour, learning and day-to-day living (Sciberras et al., 2013). Ethics approval was obtained from the relevant institutions [blinded for review]. Baseline data were collected in 2011-2012 (wave one, mean age = 7.3), with follow up data collected at 18 months (2013-2014, wave two, mean age $=8.9)$, 36 months $(2014-2015$, wave three, mean age $=10.5)$ and 54 months $(2017$, wave four, mean age $=12.0)$.

\section{Participants and Procedure}

Participants were recruited from 43 socioeconomically diverse government schools in Melbourne, Australia, using a two-stage procedure. In the first stage, parents of all children in Grade 1 at each school $(n=5,922)$ were invited to complete the Conners 3 ADHD Index (Conners, 2008) and to report whether their child had received a clinical diagnosis of ADHD. With parent consent, teachers 
were also invited to complete the Conners 3 ADHD Index. Children were excluded from participation if they had an intellectual disability, severe medical condition, genetic disorder, moderate-severe sensory impairment or neurological problems. Children with parents who had insufficient English language skills to complete interviews or questionnaires were also excluded. Complete stage one data (parent and teacher index) were obtained for 3,734 eligible children. Children were screened positive for ADHD if they had a previous ADHD diagnosis or if they scored above the relevant cut-off on the Conners 3 for both parent and teacher report $\left(75^{\text {th }}\right.$ percentile for age for boys, $80^{\text {th }}$ percentile for age for girls) ( $\mathrm{n}=412)$. In stage two, each child who screened positive for ADHD was matched with a child who screened negative for ADHD, with respect to grade level, sex and school. Families of all positive-screen and matched negative-screen children were invited to participate in the longitudinal study. Four hundred and ninety-eight families participated at baseline (267 positive-screen children, response rate: $65 \% ; 231$ negative-screen children, response rate: $56 \%$ ). The mean age of participating children was 7.3 years $(\mathrm{SD}=.4)$ at baseline.

Post-screening, consenting families participated in structured diagnostic interviews using the Diagnostic Interview Schedule for Children IV (DISC-IV) (Shaffer, Fisher, Lucas, Dulcan, \& Schwab-Stone, 2000). Results were used to define children's ADHD status (ADHD, high risk or control) and to identify other comorbid psychological disorders. Children were allocated to the ADHD group if they screened positive for ADHD and met criteria for ADHD on the DISC-IV. Children were allocated to the high risk group if they screened positive for ADHD but did not meet criteria for ADHD on the DISC-IV, or they screened negative for ADHD but did meet criteria for ADHD on the DISC-IV. Children were allocated to the control group if they screened negative for ADHD and did not meet criteria for ADHD on the DISC-IV. Direct assessments and detailed parent and teacher surveys were conducted. All interviews and assessments were completed by trained members of the research team, all of whom held a minimum four-year degree in psychology.

Assessments were conducted at the child's school or home, according to parents' preferences. Surveys were completed on paper and online. Assessor blinding to children's ADHD status was maintained at all waves.

Follow up waves of data collection involved re-administration of direct assessments and parent, teacher and child surveys. Four hundred and seventy-four families participated in wave two (mean age of participating children was 8.9 years, $\mathrm{SD}=.4$ ) and 388 families participated in wave three (mean age of participating children was 10.5 years, $\mathrm{SD}=.5$ ). Wave four targeted only families whose children participated in wave three. Two hundred and seventy-one families participated in wave four (average age of participating children was 12 years, $\mathrm{SD}=.7$ ).

\section{Measures}

Demographic information. Child age and sex, parent education level, local government area and current ADHD medication use were obtained via parent survey at each wave. 
ADHD symptoms. ADHD symptom severity was measured using teacher report on the Conners 3 ADHD Index at baseline (age 7) (Conners, 2008). The ADHD Index consists of 10 items rated on a three-point Likert scale ranging from 1 (never/seldom) to 3 (very often/very frequent). The items are summed, with higher scores indicating greater severity. Internal consistency was excellent for the current sample (Cronbach's $\alpha=.97$ ).

Student teacher relationships. Student-teacher relationships were assessed using teacher report on the Student-Teacher Relationship Scale (STRS) at wave three (age 10) (Pianta, 2001). The STRS consists of 15 items rated on a five-point Likert scale ranging from 1 (definitely does not apply) to 5 (definitely applies). Seven items measure student-teacher closeness (e.g. "If upset, this child will seek comfort from me") and eight items measure student-teacher conflict (e.g. "This child is sneaky or manipulative with me"). The items are summed, with higher scores indicating greater closeness or conflict in the relationship. Internal consistency was excellent for the current sample (Cronbach's $\alpha$ $=.82$ for the closeness subscale and .87 for the conflict subscale).

Emotional engagement with school. Children's emotional engagement with school was measured using child report on the Longitudinal Surveys of Australian Youth (LSAY) Attitudes Towards School Survey - Positive Affect (PA) subscale at waves three and four (age 10 and 12) (Longitudinal Surveys of Australian Youth, 2018). The subscale consists of six items, measured on a four-point Likert scale ranging from 1 (strongly disagree) to 4 (strongly agree), including items such as "My school is a place where I feel happy" and "My school is a place where I like learning". Internal consistency was excellent for the current sample (Cronbach's $\alpha=.82$ at wave three and .84 at wave four).

Internalising disorders, externalising disorders and ADHD type. DISC-IV parent interview was used to assess the presence of clinically significant internalising and externalising disorders, as well as the type of ADHD present (where relevant) in children at baseline (age 7) (Shaffer et al., 2000). Externalising disorders included Oppositional Defiant Disorder and Conduct Disorder. Internalising disorders included mood and anxiety disorders (Social Phobia, Separation Anxiety, Generalised Anxiety, Obsessive Compulsive Disorder, Major Depressive Disorder and Dysthymic Disorder)

Socioeconomic status (SES). SES was measured using the Australian Bureau of Statistics Socio-Economic Indexes for Areas (SEIFA) Index of Relative Socio-Economic Disadvantage (IRSD) at baseline (age 7) (Australian Bureau of Statistics, 2013). Low scores indicate relatively greater disadvantage, while higher scores indicate relative lack of disadvantage.

\section{Data Analysis}

Descriptive statistics and correlations were conducted to summarise and examine the relationships between the variables of interest in the study. Path analysis was then conducted to test the hypothesised model (see Figure 1) using Maximum Likelihood estimation in MPlus version 7.4 
(Muthén \& Muthén, 1998-2015). First, the hypothesised model was estimated. To account for the relationship between student-teacher closeness and conflict, residual error terms were correlated. The model was then estimated adjusting for covariates including participants' ADHD status (ADHD, high risk or control group membership) and SES at age 7 (baseline) and ADHD medication use at age 10 (wave three). For all models, estimates of the direct, indirect and total effects of the pathways on children's emotional engagement with school were examined. For both the unadjusted and adjusted models, model fit was assessed using the chi-square test $\left(\chi^{2}\right)$ and other fit indices including the Tucker-Lewis Index (TLI), the Comparative Fit Index (CFI) and Root Mean Square Error of Approximation (RMSEA). A non-significant chi-square indicates that the hypothesised model is a good fit to the data. For the TLI and CFI, values exceeding .90 indicate acceptable fit; RMSEA values close to or below .05 are considered acceptable fit (Hu \& Bentler, 1999). Analyses were run with complete cases and with missing data handled using the full information maximum likelihood (FIML) option in MPlus. As these analyses yielded similar fit statistics and path estimates, only the results where FIML was used to manage missing data are presented.

Finally, multi-group analyses were conducted to test whether the model differed significantly by sex (male vs female), the presence of comorbid internalising disorders (yes vs no) and externalising disorders (yes vs no), and ADHD subtype (inattentive type vs hyperactive-impulsive and combined types). For each analysis, an unconstrained model (where all structural paths were freely estimated) was compared with a constrained model (where paths were constrained to be equal), using the Satorra-Bentler scaled chi-square difference test.

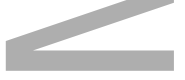

\section{Results}

\section{Participant Characteristics}

Baseline participant characteristics are displayed in Table 1. Approximately two thirds of participants were male. Participants were evenly distributed among the ADHD status groups (ADHD, high risk and control).

\section{Descriptive Statistics}

The extent of missing data was approximately $16 \%$ across all study variables, and these were missing at random as evidenced by Little's Missing Completely at Random test ( $p>.05$ ). Descriptive statistics for model variables are presented in Table 2. The Doornik-Hansen test for multivariate normality was significant ( $\mathrm{p}$.05), indicating multivariate non-normality. Maximum Likelihood estimation with robust standard errors was therefore used in the path analyses.

Correlations between the study variables are presented in Table 3. Most model variables were significantly associated with one another, except the relationships between student-teacher closeness and ADHD symptoms, and student-teacher closeness and emotional engagement with school. While student-teacher conflict was significantly associated with emotional engagement with school at age 10 (wave three), the association was not significant at age 12 (wave four). 


\section{Testing the Hypothesized Model}

The hypothesised model was an excellent fit to the data, $\chi^{2}(3, \mathrm{~N}=498)=1.47, \mathrm{p}=.69 ; \mathrm{TLI}=1.03$; $\mathrm{CFI}=1.00 ; \mathrm{RMSEA}=.00$ (90\% confidence interval $=.00-.06)$. The model significantly accounted for $31 \%$ of the variance in emotional engagement with school at age $12\left(\mathrm{R}^{2}=.31, \mathrm{p}<.001\right) ; 12 \%$ of the variance in emotional engagement with school at age $10\left(\mathrm{R}^{2}=.12, \mathrm{p}<.001\right)$; and $19 \%$ of the variance in student-teacher conflict $\left(\mathrm{R}^{2}=19, \mathrm{p}<.001\right)$.

To account for participants' ADHD medication use, ADHD status and SES, the hypothesised model was adjusted to include covariates. Although 10 cases were excluded due to missing data on the covariates, the adjusted model remained an excellent fit to the data, $\chi^{2}(6, \mathrm{~N}=488)=7.59, \mathrm{p}=.27$; TLI $=.97 ; \mathrm{CFI}=.99$; RMSEA $=.02(90 \%$ confidence interval $=.00-.07)$. The adjusted model significantly accounted for $32 \%$ of the variance in emotional engagement with school at age $12\left(\mathrm{R}^{2}=.32, \mathrm{p}<.001\right) ; 12 \%$ of the variance in emotional engagement with school at age $10\left(R^{2}=.12, p<.001\right)$; and $20 \%$ of the variance in student-teacher conflict $\left(R^{2}\right.$ $=.20, \mathrm{p}<.001)$.

As standardised parameter estimates for the unadjusted and adjusted models were similar, only the adjusted standardised parameter estimates are shown in Figure 1.

Higher ADHD symptoms at age seven were significantly associated with lower emotional engagement with school at age 10. Higher ADHD symptoms at age seven were also significantly associated with higher student-teacher conflict at age 10, which in turn was significantly associated with lower emotional engagement with school at age 10. Emotional engagement with school at age 10 was significantly associated with emotional engagement with school at age 12 .

The total indirect effect of ADHD symptoms on emotional engagement with school at age 12 via student-teacher relationships and emotional engagement with school at age 10 was significant $(-.13, \mathrm{p}<.001)$. Specific indirect pathways via conflict and via emotional engagement with school at age 10 were significant $(-.03, \mathrm{p}=.03$; and $-.10, \mathrm{p}=.01$ respectively). The strongest indirect pathway was via emotional engagement with school at age 10 . The indirect effect via student-teacher closeness at age 10 was not significant $(.00, \mathrm{p}=$ $.85)$.

Multi-group analyses were conducted to test whether sex, comorbid internalising and externalising disorders, or ADHD subtype moderated any of the paths in the model. Lack of significant differences between the constrained and unconstrained models for sex, externalising disorders and ADHD subtype suggested there was no evidence of moderation, as summarised in Table 4. The model did not converge for internalising disorders. This was likely due to the limited sample size for internalising disorders $(n=65)$.

\section{Discussion}

This study explored the impact of ADHD symptoms on children's emotional engagement with school, investigating student-teacher closeness and conflict as mediating variables. As hypothesised, ADHD symptom severity at age seven significantly predicted children's emotional engagement with school at age 10, which was in turn a significant predictor of their emotional engagement with school at age 12. ADHD symptom severity significantly predicted student-teacher conflict, which partially mediated the association between ADHD symptoms and emotional engagement with school. These associations remained significant after This article is protected by copyright. All rights reserved 
controlling for differences in ADHD status (ADHD, high risk or control group), ADHD medication use and socio-economic status. Contrary to expectations, ADHD symptoms did not significantly predict studentteacher closeness, and student-teacher closeness did not significantly predict emotional engagement with school.

As hypothesised, the pathways in the model were similar for boys and girls. This suggests that the mechanisms by which ADHD symptoms impact emotional engagement with school (directly and via studentteacher conflict) operate similarly for both sexes. Counter to expectations, there was no evidence that model pathways were stronger for children with combined or hyperactive-impulsive type ADHD or for those children with comorbid externalising disorders.

Taken together, the results indicate that ADHD symptom severity is an important risk factor for lower emotional engagement with school in the primary years, irrespective of child sex, ADHD sub-type or the presence of comorbid externalising disorders. The more ADHD symptoms children displayed in early primary school, the less positively they felt about their school and their learning in middle and upper primary school. These findings build on previous research by providing evidence for the strong association between ADHD symptoms and children's emotional engagement with school. While previous research examining the impact of ADHD on emotional engagement with school has yielded mixed results, the current study clarifies the association, showing that emotional engagement with school is negatively impacted by ADHD symptoms, and is thus a worthy target of intervention.

Our findings indicate that higher ADHD symptoms are associated with lower emotional engagement with school directly, and also indirectly via increased student-teacher conflict. The more ADHD symptoms children displayed in early primary school, the more conflict teachers reported in their relationships with those students in middle primary school, which was associated with lower student-reported emotional engagement with school. When children experience many ADHD symptoms in the classroom, this often leads to disruption of their learning and the classroom environment. This in turn attracts negative interactions with teachers, as they intervene to provide support to maintain attention and implement consequences for behaviour. The experience of these conflictual interactions impacts negatively on student-teacher relationships, as well as students' feelings about school and their learning. The stronger pathway via conflict (compared to closeness), underscores the contribution of conflict in the student-teacher relationship to children's lower emotional engagement with school. This is consistent with evidence from previous research that child mental health problems are more closely linked to student-teacher conflict than to closeness (Drugli, 2013; Murray \& Murray, 2004). However, this study did not replicate previous findings in relation to the negative association between ADHD and student-teacher closeness (Portilla et al., 2014; Rogers \& Toste, 2015; Birch \& Ladd, 1998). Given that previous research examining the impact of ADHD on student-teacher relationships has been conducted largely in North America, cultural factors may account for this different result. That ADHD symptoms did not significantly predict student-teacher closeness in the present study is encouraging, in that it suggests that ADHD symptom severity does not significantly impact the positive aspects of children's relationships with their teachers, from the teacher perspective. It would be beneficial to examine this from the child's perspective in future research.

This article is protected by copyright. All rights reserved 
In the present study, emotional engagement with school at age 10 was a strong predictor of emotional engagement with school at age 12. This provides further evidence that school engagement patterns start early in students' school careers and are maintained over time (Hancock \& Zubrick, 2015), and highlights the importance of intervening in primary school to support students to develop positive school engagement. This is particularly important for children with ADHD who are at greater risk of lower emotional engagement with school.

\section{Strengths, Limitations and Future Directions}

The study design had major strengths, including analysis of data collected at three time-points from multiple raters, allowing inferences to be made about directionality of the effects. Importantly, the study captured the child's voice via self-report of emotional engagement with school. Compared with clinical recruitment, the community-based recruitment procedure implemented maximises generalisability of the results, by minimising the risk of overrepresentation of boys and more severe cases of ADHD, as well as the risk of underrepresentation of inattentive type ADHD in the sample (Efron et al., 2014). In addition, the dimensional approach to ADHD symptoms enabled consideration of the impact of ADHD symptom severity, irrespective of clinical ADHD diagnosis, in contrast with previous studies which have compared categorically defined ADHD with control groups.

The study also had some limitations. First, there are many factors that likely impact on school engagement for children with ADHD that were not included in the present model. Future research may consider a role for academic skills (Corkum, McGonnell, \& Schachar, 2010), peer relationships (Gardner \& Gerdes, 2015), selfworth (Kita \& Inoue, 2017) and family factors (Lam et al., 2016; Johnston \& Chronis-Tuscano, 2017). Further, the present study considered only unidirectional effects between student-teacher relationships and emotional engagement with school. It is possible that these effects may be bidirectional over time (Hamre \& Pianta, 2001). Examining the stability of student-teacher conflict for children with ADHD over time is also likely to yield useful insights. The present study did not investigate the impact of teacher characteristics (i.e., sex, professional experience and training, attitudes towards students with ADHD) or school characteristics (i.e., school behavioural policies, support available for teachers). Investigating these factors may shed further light on the relationships between ADHD symptoms, student-teacher conflict and emotional engagement with school, providing information that could be useful to develop and promote successful interventions. Further, this study considered only teacher report of student-teacher relationships; examining the student perspective will be an important direction for future research. Finally, children whose parents had insufficient English language skills to participate in interviews and complete surveys were excluded from the present study, limiting the representative nature of the sample. Future research should be targeted at understanding school engagement in culturally and linguistically diverse children with ADHD, as these children are likely to be among the most vulnerable to poor school-level outcomes (Goldfeld, O'Connor, Mithen, Sayers, \& Brinkman, 2014).

Given the dearth of research examining school engagement in the context of ADHD, further studies are required in this area. In particular, more longitudinal work that differentiates and examines the three school engagement components over time will be useful to build a more complete picture of the impact of ADHD on This article is protected by copyright. All rights reserved 
school engagement, the effect of this on children and young people's functional outcomes, and what intervention and support is required to improve these outcomes. Mixed-methods approaches may be useful to more comprehensively capture the views, opinions and experiences of students with ADHD. This information can then be used to provide direction to families, teachers and education systems as they support children with ADHD to navigate the complex challenges of their school years.

\section{Implications and Conclusions}

Findings from the present study highlight the negative impact of ADHD symptoms on children's emotional engagement with school in the primary years, emphasising the key role of student-teacher conflict as an important contributing factor. Given the important role of student-teacher conflict in mediating the negative association between ADHD symptoms and children's emotional engagement with school, the present findings suggest that interventions aiming to reduce conflict in the student-teacher relationship are worthy of investigation. Results of the present study suggest that the reduction of conflict in student-teacher relationships may be an effective mechanism to promote school engagement for students with a diagnosis of ADHD, as well as those who present with sub-clinical (or undiagnosed) ADHD symptoms.

Our results support previous calls for teachers to be empowered to understand their important role in promoting school engagement, particularly for at risk students (Murray \& Murray, 2004), including those with ADHD. While training to improve teachers' capacity to implement preventative behaviour management strategies and minimise conflict in the classroom will be beneficial, intervention may be most effective when targeted directly at reducing student-teacher conflict in individual student-teacher relationships. Providing both the student and teacher with direct support to develop skills to relate in a more supportive and less conflictual way is important, as multi-level, multi-component intervention efforts will likely be more effective than targeting intervention at the teacher or student alone (Murray \& Murray, 2004).

School is a very challenging environment for children with ADHD. Translating the present findings into educational practice is critical, as intervention to promote positive emotional engagement with school in the primary years has potential to improve school engagement trajectories for this vulnerable population of students. Supporting children with ADHD to have more positive experiences in the classroom, with opportunities to build more supportive, less conflictual relationships with teachers, will likely assist them to develop more positive feelings about their learning and the school they attend. By intervening to support emotional engagement with school in the primary years, this approach may help to improve educational and occupational outcomes for individuals with ADHD across the lifespan.

\section{References}

Archambault, I., Vandenbossche-Makombo, J., \& Fraser, S. L. (2017). Students' Oppositional Behaviors and Engagement in School: The Differential Role of the Student-Teacher Relationship. Journal of Child and Family Studies, 26(6), 1702-1712. doi:10.1007/s10826-017-0691-y

Australian Bureau of Statistics. (2013). Census of Population and Housing: Socio-Economic Indexes for Areas (SEIFA). Retrieved from http://www.abs.gov.au/

Conners, C. K. (2008). Conners 3rd Edition. Torono, Canada: Multi-health systems. 
Drugli, M. B. (2013). How are Closeness and Conflict in Student-Teacher Relationships Associated with Demographic Factors, School Functioning and Mental Health in Norwegian Schoolchildren Aged 613? Scandinavian Journal of Educational Research, 57(2), 217-225. doi:10.1080/00313831.2012.656276

Faraone, S. V., Asherson, P., Banaschewski, T., Biederman, J., Buitelaar, J. K., Ramos-Quiroga, J. A., . . . Franke, B. (2015). Attention-deficit/hyperactivity disorder. Nature Reviews Disease Primers, 1, 15020. doi:10.1038/nrdp.2015.20

Fredricks, J. A., Filsecker, M., \& Lawson, M. A. (2016). Student engagement, context, and adjustment: Addressing definitional, measurement, and methodological issues. Learning and Instruction, 43, 1-4. doi:10.1016/j.learninstruc.2016.02.002

Furrer, C., \& Skinner, E. (2003). Sense of relatedness as a factor in children's academic engagement and performance. Journal of Educational Psychology, 95(1), 148-162. doi:10.1037/0022-0663.95.1.148

Gardner, D. M., \& Gerdes, A. C. (2015). A Review of Peer Relationships and Friendships in Youth With ADHD. Journal of Attention Disorders, 19(10), 844-855. doi:10.1177/1087054713501552

Goldfeld, S., O'Connor, M., Mithen, J., Sayers, M., \& Brinkman, S. (2014). Early development of emerging and English proficient bilingual children at school entry in an Australian population cohort. International Journal of Behavioral Development, 38, 42-51. doi:10.1177/0165025413505945

Hamre, B. K., \& Pianta, R. C. (2001). Early Teacher-Child Relationships and the Trajectory of Children's School Outcomes through Eighth Grade. Child Development, 72(2), 625-638. doi:10.1111/14678624.00301

Hu, L. T., \& Bentler, P. M. (1999). Cutoff criteria for fit indexes in covariance structure analysis: conventional criteria versus new alternatives. Structural Equation Modeling: A Multidisciplinary Journal, 6, 1-55. doi:10.1080/10705519909540118

Lam, S. F., Jimerson, S., Wong, B. P., Kikas, E., Shin, H., Veiga, F. H., . . Zollneritsch, J. (2014). Understanding and measuring student engagement in school: the results of an international study from 12 countries. School Psychology Quarterly, 29(2), 213-232. doi:10.1037/spq0000057

Longitudinal Surveys of Australian Youth. (2018). About LSAY. Retrieved from https://www.lsay.edu.au/aboutlsay

Martin, A. J.(2012), Attention-Deficit/Hyperactivity Disorder (ADHD), Perceived Competence, and SelfWorth: Evidence and Implications for Students and Practitioners. In D. Hollar (Ed.), Handbook on Children with Special Health Care Needs (pp. 47-72). New York, NY: Springer.

Mason, B. A., Hajovsky, D. B., McCune, L. A., \& Turek, J. J. (2017). Conflict, Closeness, and Academic Skills: A Longitudinal Examination of the Teacher-Student Relationship. School Psychology Review, 46(2), 177-189. doi:10.17105/spr-2017-0020.v46-2

Mautone, J. A., Lefler, E. K., \& Power, T. J. (2011). Promoting Family and School Success for Children With ADHD: Strengthening Relationships While Building Skills. Theory into Practice, 50(1), 43-51. doi:10.1080/00405841.2010.534937 
Murray, C., \& Murray, K. M. (2004). Child level correlates of teacher-student relationships: An examination of demographic characteristics, academic orientations, and behavioral orientations. Psychology in the Schools, 41(7), 751-762. doi:10.1002/pits.20015

Muthén, L., \& Muthén, B. (1998-2015). MPlus user's guide. Los Angeles, CA: Muthén \& Muthén.

Pianta, R. C., Hamre, B. K., \& Allen, J. P. (2012). Teacher-student relationships and engagement: Conceptualising, measuring, and improving the capacity of classroom interactions. In S. L. Christenson, A. L. Reschly, \& C. Wylie (Eds.), Handbook of research on student engagement (pp. $365-386)$.

Portilla, X. A., Ballard, P. J., Adler, N. E., Boyce, W. T., \& Obradovic, J. (2014). An integrative view of school functioning: transactions between self-regulation, school engagement, and teacher-child relationship quality. Child Development, 85(5), 1915-1931. doi:10.1111/cdev.12259

Quin, D. (2017). Longitudinal and Contextual Associations Between Teacher-Student Relationships and Student Engagement. Review of Educational Research, 87(2), 345-387. doi:10.3102/0034654316669434

Ramos-Díaz, E., Rodríguez-Fernández, A., Fernández-Zabala, A., Revuelta, L., \& Zuazagoitia, A. (2016). Adolescent Students Perceived Social Support, Self-Concept and School Engagement // Apoyo social percibido, autoconcepto e implicación escolar de estudiantes adolescentes. Revista de Psicodidactica / Journal of Psychodidactics, 21(2), 339-356. doi:10.1387/RevPsicodidact.14848

Raufelder, D., Sahabandu, D., Martínez, G. S., \& Escobar, V. (2013). The mediating role of social relationships in the association of adolescents' individual school self-concept and their school engagement, belonging and helplessness in school. Educational Psychology, 35(2), 137-157. doi:10.1080/01443410.2013.849327

Reynolds, C. R., \& Kamphaus, R. W. (2003). Handbook of Psychological and Educational Assessment of Children: Personality, Behaviour and Context (2nd ed.). New York, NY: Guilford.

Rogers, M., Bélanger-Lejars, V., Toste, J. R., \& Heath, N. L. (2015). Mismatched: ADHD symptomatology and the teacher-student relationship. Emotional and Behavioural Difficulties, 20(4), 333-348. doi:10.1080/13632752.2014.972039

Sciberras, E., Efron, D., Schilpzand, E. J., Anderson, V., Jongeling, B., Hazell, P., . . Nicholson, J. M. (2013). The Children's Attention Project: a community-based longitudinal study of children with ADHD and non-ADHD controls. BMC Psychiatry, 13(18). doi:10.1186/1471-244X-13-18

Shaffer, D., Fisher, P., Lucas, C. P., Dulcan, M. K., \& Schwab-Stone, M. E. (2000). NIMH Diagnostic Interview Schedule for Children Version IV (NIMH DISC-IV): description, differences from previous versions and reliability of some common diagnoses. Journal of the American Academy of Child \& Adolescent Psychiatry, 39(1), 28-38. doi:10.1097/00004583-200001000-00014

Skinner, E., Furrer, C., Marchand, G., \& Kindermann, T. (2008). Engagement and disaffection in the classroom: Part of a larger motivational dynamic? Journal of Educational Psychology, 100(4), 765781. doi:10.1037/a0012840 
Steinberg, E. A., \& Drabick, D. A. (2015). A Developmental Psychopathology Perspective on ADHD and Comorbid Conditions: The Role of Emotion Regulation. Child Psychiatry and Human Development, 46(6), 951-966. doi:10.1007/s10578-015-0534-2

Wang, M. T., \& Fredricks, J. A. (2014). The reciprocal links between school engagement, youth problem behaviors, and school dropout during adolescence. Child Development, 85(2), 722-737. doi:10.1111/cdev. 12138

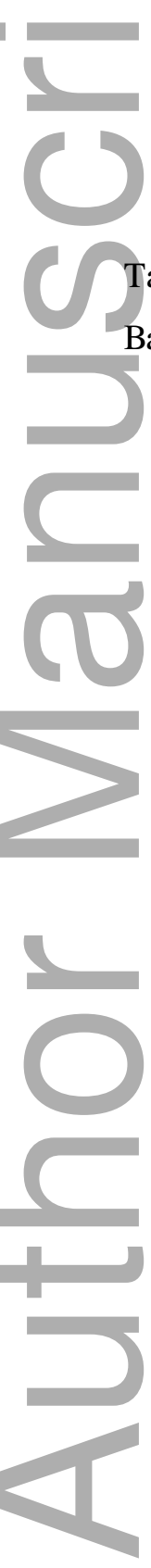

Table 1

Baseline participant characteristics (at age seven)

Participant characteristics

Male, $\mathrm{n}(\%)$

ADHD status, n (\%)

ADHD

$179(35.9)$

High risk

$100(20.1)$

Control

$212(42.6)$

ADHD subtype, n (\%)

Inattentive

72 (14.5)

Hyperactive-Impulsive

Combined

94 (18.9)

ADHD medication use, $\mathrm{n}(\%)^{\mathrm{a}}$

ADHD

27 (21.4)

High risk

4 (5.6)

Control

$0(0)$

Internalising disorder, $\mathrm{n}(\%)$

65 (13.1)

Externalising disorder, $\mathrm{n}(\%)$

$138(27.7)$

SES, M (SD)

$1015.5(44.8)$

Primary carer university completion, $\mathrm{n}(\%)$

ADHD

$41(24.6)$

High risk

$36(46.8)$

Control

$95(47.0)$

Note. $\mathrm{N}=498$.

${ }^{\mathrm{a}} \mathrm{ADHD}$ medication use measured at age 10 (wave three) $(\mathrm{N}=342)$. 
Table 2

Descriptive statistics

\begin{tabular}{lcccccc}
\hline & M & SD & Minimum & Maximum & Skewness & Kurtosis \\
\hline ADHD symptoms (at age seven) & 6.77 & 7.10 & 0 & 20 & 0.55 & 1.77 \\
Student-teacher relationship (at age 10) & & & & & & \\
$\quad$ Closeness & 32.47 & 4.96 & 18 & 40 & -0.52 & 2.78 \\
$\quad$ Conflict & 10.67 & 5.39 & 7 & 33 & 1.99 & 6.74 \\
Emotional engagement (at age 10) & 3.21 & 0.51 & 1.5 & 4 & -0.61 & 3.27 \\
Emotional engagement (at age 12) & 3.19 & 0.52 & 1.67 & 4 & -0.49 & 3.07 \\
\hline
\end{tabular}

Note. N ranged from a maximum of 498 to a minimum of 264. 


\section{Table 3}

Correlations among study variables

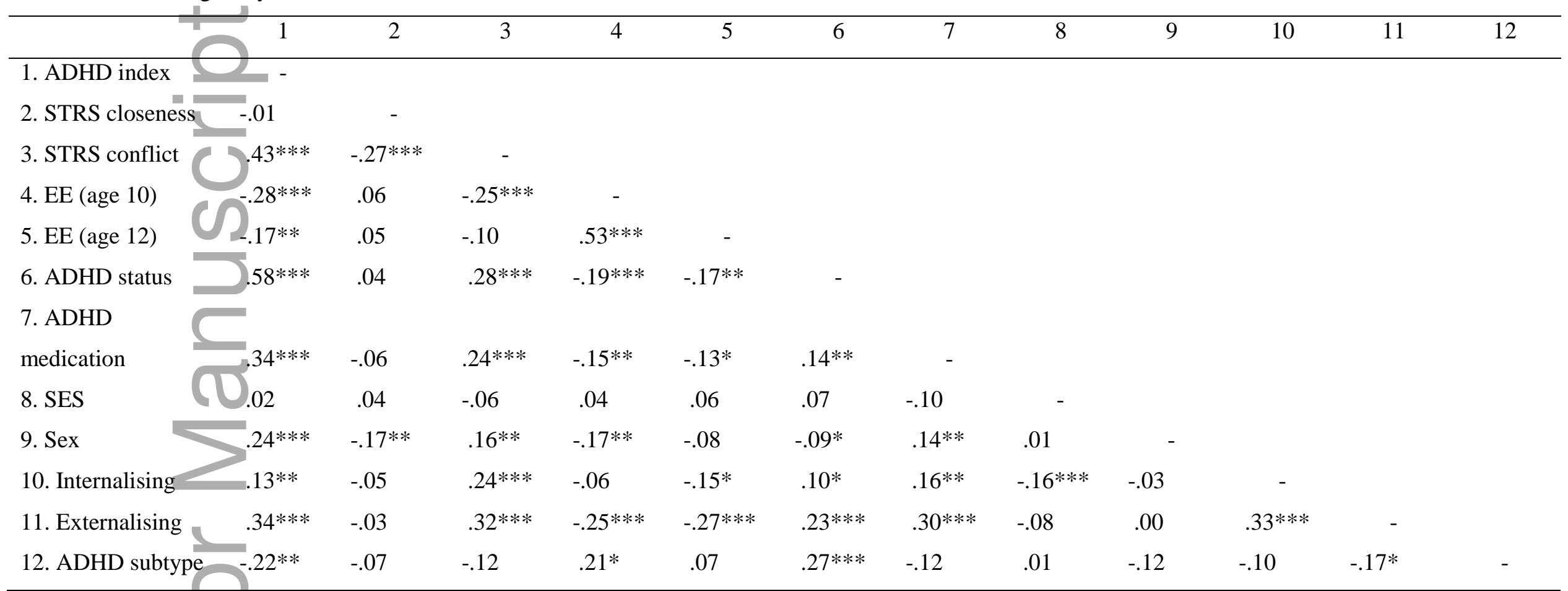

$* \mathrm{p}<0.05, * * \mathrm{p}<0.01, * * * \mathrm{p}<0.001$

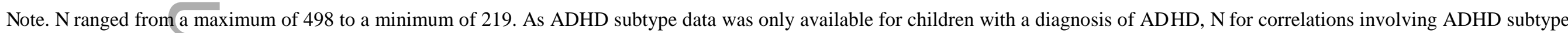
ranged from 194 to 105 .

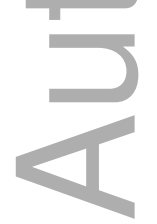

This article is protected by copyright. All rights reserved 
Table 4

Multigroup comparisons for child sex, externalising disorders and ADHD subtype

\begin{tabular}{|c|c|c|c|}
\hline Multigroup analyses & $\chi^{2}$ & $\mathrm{df}$ & Satorra-Bentler scaled $\chi^{2}$ difference test $(\mathrm{df})$ \\
\hline \multicolumn{4}{|c|}{ Child sex (male $n=303$, female $n=185$ ) } \\
\hline Unconstrained & 10.79 & 12 & \\
\hline Constrained & 34.06 & 33 & $23.24(21)^{\mathrm{ns}}$ \\
\hline \multicolumn{4}{|c|}{ Externalising disorders $($ yes $n=137$, no $n=345$ ) } \\
\hline Unconstrained & 18.26 & 12 & \\
\hline Constrained & 34.42 & 30 & $15.86(18)^{\mathrm{ns}}$ \\
\hline \multicolumn{4}{|c|}{ ADHD subtype (inattentive type $n=71$, hyperactive-impulsive/combined type $n=119$ ) } \\
\hline Unconstrained & 16.98 & 12 & \\
\hline Constrained & 42.62 & 30 & $25.67(18)^{\mathrm{ns}}$ \\
\hline
\end{tabular}

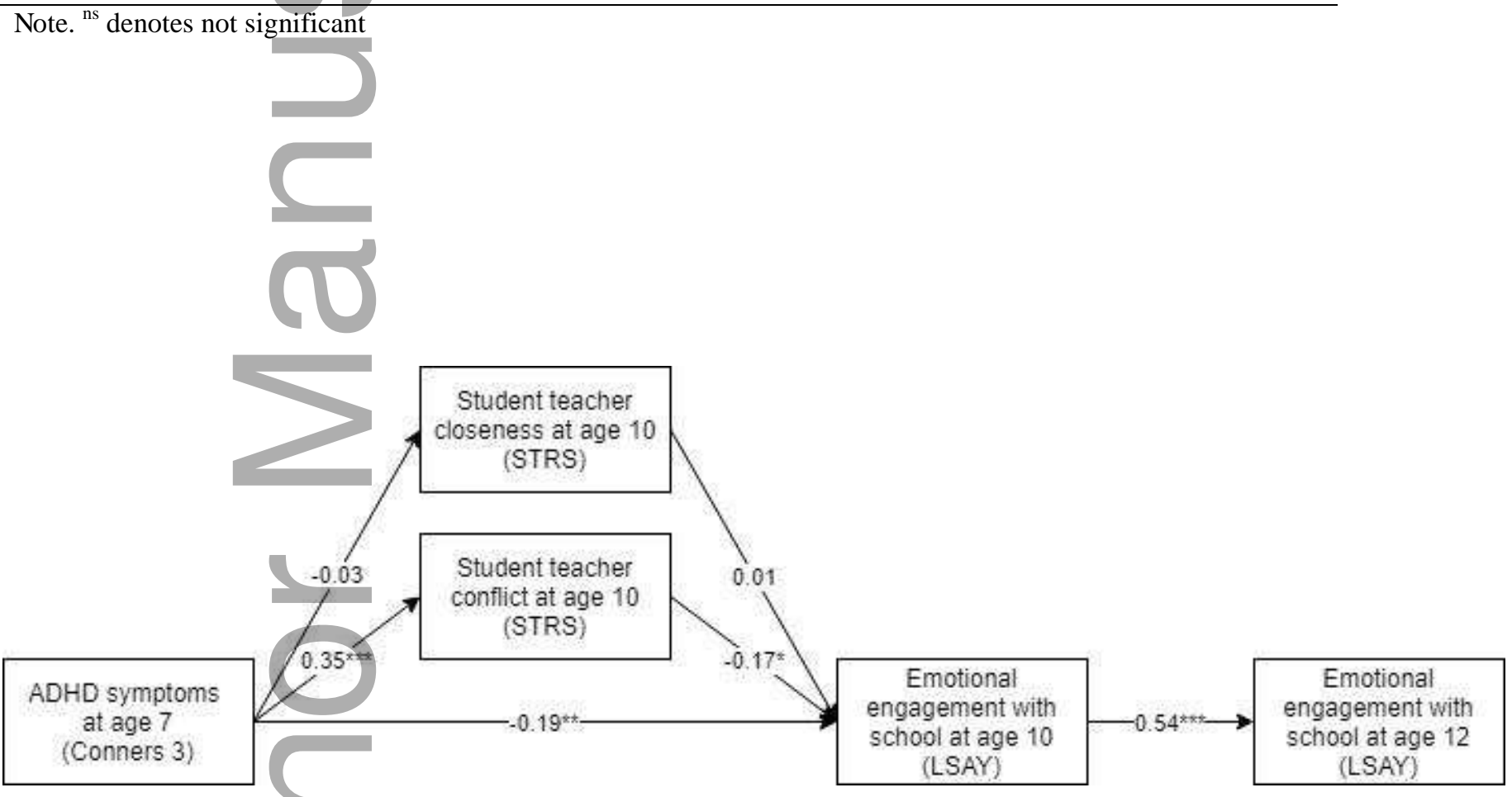

Figure 1. Standardised coefficients for the hypothesised model adjusted for ADHD medication status, ADHD diagnosis status and socioeconomic status.

$* \mathrm{p}<.05 ; * * \mathrm{p}<.01 ; * * * \mathrm{p}<.001$.

Note. Residual error terms between student teacher closeness and conflict were correlated. 


\section{University Library}

\section{- M I N E R VA \\ A gateway to Melbourne's research publications}

Minerva Access is the Institutional Repository of The University of Melbourne

Author/s:

Rushton, S;Giallo, R;Efron, D

Title:

ADHD and emotional engagement with school in the primary years: Investigating the role of student-teacher relationships

Date:

2019-10-26

\section{Citation:}

Rushton, S., Giallo, R. \& Efron, D. (2019). ADHD and emotional engagement with school in the primary years: Investigating the role of student-teacher relationships. BRITISH JOURNAL OF EDUCATIONAL PSYCHOLOGY, 90 (S1), pp.193-209. https://doi.org/10.1111/ bjep. 12316.

Persistent Link:

http://hdl.handle.net/11343/286926 